\title{
Integrated Science: Florida Manatees and Everglades Hydrology
}

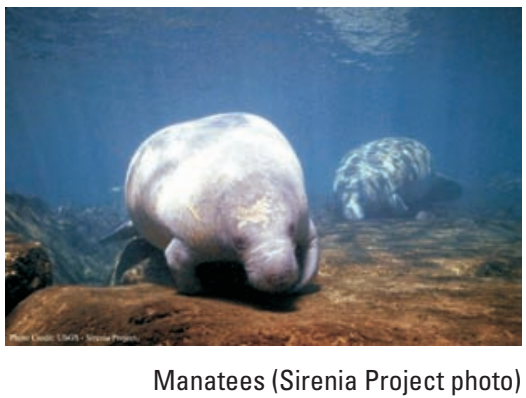

\section{Introduction}

Restoration of the Everglades requires the implementation of dozens of separate construction components staggered over time and across the landscape; thus, effects on habitat and species will be realized on different time and spatial scales. Predicting and monitoring restoration effects on Florida manatees, which are known to make extended movements, will be incomplete if modeling and monitoring are limited to the smaller areas defined by the various restoration components. U.S. Geological Survey (USGS) efforts, thus far, have focused on (1) collecting manatee movement data throughout the Ten Thousand Islands (TTI) region, and (2) developing an individual-based model for manatees to illustrate manatee responses to changes in hydrology

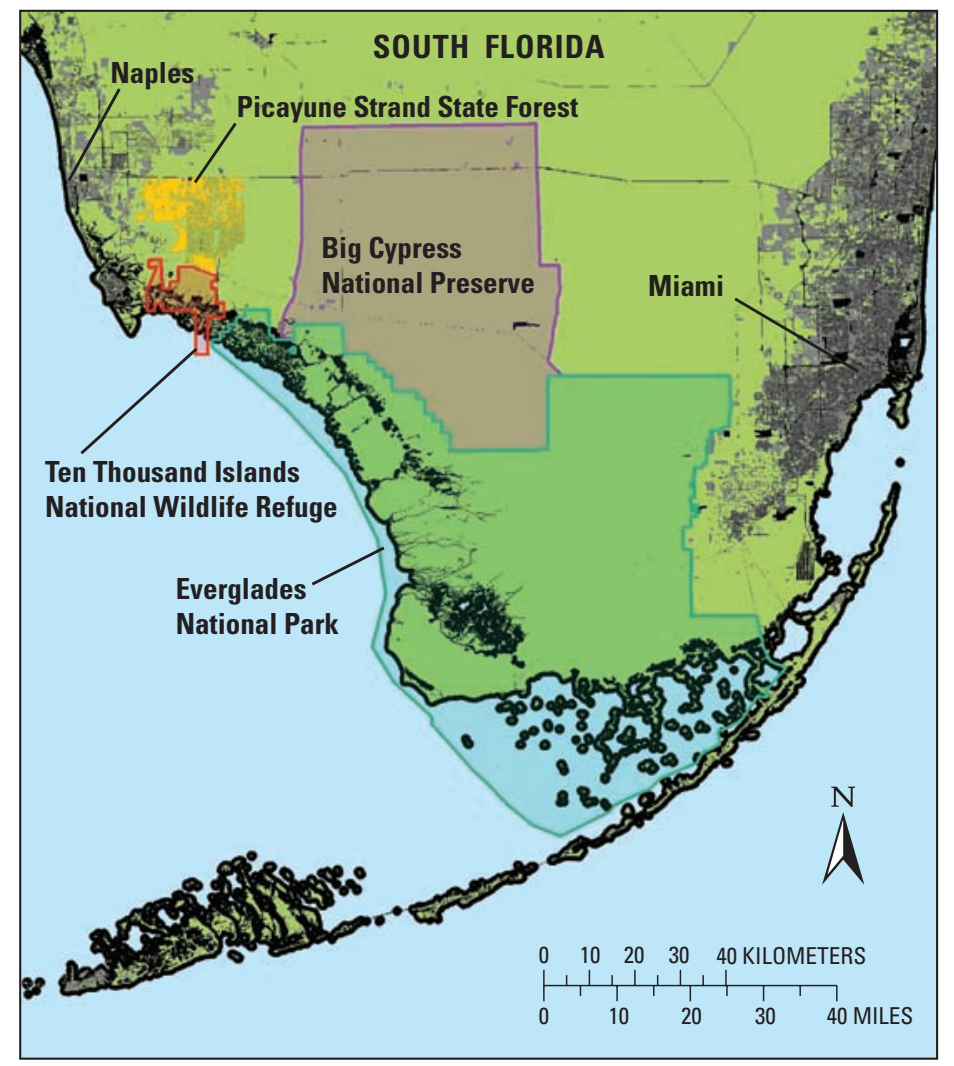

related to the Picayune Strand Restoration Project (PSRP) (fig. 1). In 2006, new regional research was begun to extend an Everglades hydrology model into the TTI region; extend the manatee movement model into the southern estuaries of Everglades National Park (ENP); and integrate hydrology and manatee data, models, and monitoring across the TTI region and ENP. Currently (2008), three research tasks are underway to develop the necessary modeling components to assess restoration efforts across the Greater Everglades Ecosystem.

\section{Linking the Manatee Individual-Based Model with a New Ten Thousand Islands Hydrology Model and an Everglades Model}

To evaluate how proposed restoration changes will affect the endangered manatee, it is necessary to (1) apply the Flow and Transport in a Linked Overland/Aquifer Density Dependent System (FTLOADDS) hydrology model to the Everglades area covered by the Tides and Inflows in the Mangroves of the Everglades (TIME) hydrology model, (2) extend the TIME model into the TTI area, and (3) integrate the hydrology model output with an individual-based manatee model. The FTLOADDS model simulates key hydrologic parameters that manatees respond to, including salinity, water level, and water temperature. To improve its value for evaluating manatees across the Greater Everglades, the model is being developed and applied in the TTI region south of U.S. Highway 41, including the PSRP area and the Big Cypress region. This objective is critical because both areas are important to manatees and are identified as priorities in the U.S. Department of the Interior Science Plan. Telemetry data collected from radio-tracked manatees in the region will be analyzed to help calibrate the FTLOADDS model and parameterize the response of manatees to restoration (fig. 2).

Figure 1. Study area, showing general locations of the Ten Thousand Islands and Everglades National Park, south Florida. 